\title{
ANALYSIS OF THE AGILITY OF THE AUTOMOTIVE INDUSTRY SUPPLY CHAIN IN TIMES OF COVID-19: A CASE STUDY
}

\author{
Fadoua Tamtam $\bowtie$ \\ Systems engineering laboratory and decision support \\ National School of Applied Sciences ${ }^{1}$ \\ fadoua.tamtam@gmail.com \\ Amina Tourabi \\ Systems engineering laboratory and decision support \\ National School of Applied Sciences ${ }^{1}$ \\ ${ }^{1}$ Ibn Zohr University \\ Tamesoult ave., Agadir, Morocco, 80000
}

$\triangle$ Corresponding author

\begin{abstract}
In the early stages of the corona virus pandemic, business environment was changing rapidly. The Moroccan automotive industry was one of the export sectors most affected negatively by the corona crisis; it collapsed during the three months of confinement and the pandemic has created immense uncertainties in demand and disrupted global supply chains. Indeed, to save the automotive industry, Morocco relies on its competitiveness and challenges current supply models for supply chain agility in order to better prepare for future disruptions. Achieving a competitive edge requires aligning company with suppliers and customers as well as working together to achieve agility, organizationally, strategically and individually. However, agile supply chains are the most powerful competitive vehicles of the manufacturing companies. To help automakers deal with the many challenges associated with the pandemic, let's present this research on the key enablers that will need to be monitored as the situation evolves. Thus, our article presents an original approach which, by linking the competitive priorities, agile supply chain attributes and enablers, aims at evaluates and enhances supply chain agility of a Moroccan automotive factory. Let's adopt fuzzy quality function deployment (FQFD) approach and, in particular, the two houses of quality (HOQ) with a fuzzy scale in order to identify the most appropriate enablers to be implemented by the factory. This evaluation demonstrates that there are three enablers needing maximum attention: process compliance, logistics and distribution capabilities and supportive information technology. Then, the supply chain agility improvement should be based on these enablers.

Keywords: agility, assessment, attributes, enablers, competitive, fuzzy, automotive, corona, supply, chain.
\end{abstract}

DOI: $10.21303 / 2461-4262.2021 .001949$

\section{Introduction}

Due to customers changing requirements [1] intensified marketing competition [1-3] demand uncertainty [1], business environment complex [4] globalization [5], rapid technological innovations [2, 6], decreased lifecycles of products, diminished margins [5], growing market segmentation [6] and economic downsized markets [5], the contemporary manufacturing companies strive to become competitive [4], more responsive and more efficient thereby driving the interest in more competitive enterprise strategies [5] to achieve a level of agility, in particular in terms of agile supply chain (ASC) [4]. ASC has been identified as a critical factor to better synchronize supply with demand, it align firm with suppliers, the suppliers of the suppliers, customers and the customers of the customers, and even with competitors [7]. Thus, effective supply chain agility has become a potentially valuable way for achieving a competitive advantage, improving customer service, enhancing firm's performance and profitability [3].

Recent scientific literature of supply chain has addressed [5] the agile attributes (ASCA) which allow it to promptly respond to changes in business environment [8]. However, different attributes would lead to different levels of competitive bases (CB) [8]. In addition, agile attributes depends upon the competitive priorities the companies are willing to excel in [8]. Moreover, companies can exploit several enablers (ASCE) to achieve the attributes [8]. By reviewing conceptual models specific to ASC, none linked CB to ASCA, then ASCA to ASCE. This paper makes an attempt to fill this lack, by developing an integrated framework for supply chain agility implementation. Moreover, main objective 
of this study is to introduce a practical tool, which could be easily adopted by manufacturing companies [8], especially those operating in Moroccan automotive industry. Therefore, let's believe that this industry is an excellent dynamic context where factories adjust to significant changes more often [9], in particular in the early stages of the coronavirus pandemic. This pandemic has crippled Moroccan supply chain for the automotive sector that suffered with a demand crisis during the lockdown period, which is the case all over the world.

Given these considerations this paper begins by reviewing the literature related to supply chain agility. Then, a conceptual framework of the supply chain agility with specific attributes and enablers are developed [10]. Therefore, the purpose is to identify the principal obstacles to improvement of supply chain agility, with a particular focus on analyzing the link between $\mathrm{CB}$ with their corresponding attributes, and the attributes with their corresponding enablers. The development of a practical case is presented by selecting a Moroccan factory according to its needs to prioritize CB, identify ASCA and ASCE [11].

\section{Materials and methods}

\section{1. Supply chain agility model}

Recently, agile supply chain has been presented as an essential supporting concept for organization agility [5], and to perceive this concept, it is important to present its several definitions of it from different theoretical perspectives [3].

Firstly, ASC was defined as the ability of the supply chain to quickly align its operations to the dynamic environment [12]. It's the responsiveness and readiness of the supply chain to changes demand [12], in terms of quality, quantity and variety [9]. Also, [13] presented a unifying general definition of ASC as the ability of the supply chain to be alert to changes by using resources to responding (proactively/reactively) to these changes [13].

From the capability dynamic perspective, ASC is presented as a fundamental and a higher order [14] capability needed to cope to environment volatility, as it allows for enhancing the operational performance of the firm [9]. From the agile manufacturing perspective, ASC is a manufacturing strategy allowing supplier involvement, internal integration, and modularization of products [15]. Furthermore, SCA is typically considered to extend the concept of speed, flexibility and agility [9] as it is defined by [16] as a flexible supply chain adapting quickly to rapidly changing customer demand [3]. As the levels of speed increases, flexibility increases too and then the level of ASC [17].

Thus, ASC offers many advantages such as timely products with better quality, low costs, short life cycle and [6], as well as better supply patterns [9], by exploiting internal and external competencies to better meet the customer' s needs [14]. In practice, ASC is realized through customer effectiveness to deal with environment complexities [14] by integrating suppliers, designers, manufacturers and distribution centres [6] (stakeholders [14]) and linking them by the forward flow of products and information [6].

Several criteria for competitiveness have emerged within the first half of the 1990s [18]. From agility context, Dove $[19,18]$ conceptualized agility as the successful exploration of different competitive priorities [7], as responsiveness, new product introduction, delivery [18], flexibility [18], quality, concern for the environment and international competitiveness), speed, flexibility, cost, innovation, pro-activity, quality and profitability.

To achieve a high competitive advantage, a supply chain has to acquire some key capabilities associated with agility [20]. The first capability is flexibility which means the firm ability to adjust [21] or react with little penalty in time, effort, cost or performance [20]. It is broken down into seven attributes (product, mix, volume, delivery, procurement/sourcing, manufacturing and distribution logistics flexibility [13]). Other authors cited that an enhanced responsiveness is also a major capability of an agile supply chain [20]. It's the ability to respond to change within an appropriate time frame and it's broken down into three attributes (reactivity, velocity and visibility) [20]. A complementary capability is mentioned, in particular in a flexible environment, an agile supply chain needs to combine responsiveness with effectiveness [20]. This capability is composed of four attributes: completeness, reliability, productivity [20], cost minimization and new product development [22]. For [23], the foundation of the agile supply chain lies in the integration of five capabilities: customer (market) sensitivity, virtual organization, processes, networks and information systems [23]. Market sensitivity is the main 
capability to transform the supply chain into an agile entity. It incorporates daily P.O.S. feedback, capture emerging trends, listen to consumers [24], responding to real demand, demand for customized products, fast introduction of new products, retain and grow customer relationships, customer-based measures, improved quality, cost reduction and increased frequency of product improvements [25].

Agile supply chains are presented as the centre of networks of material and information flows [25]. Then, the network integration requires that companies leverage partners' capabilities in the chain [26], focus on core competencies, act as network orchestrator [24], top management commitment to agile practices, decentralized decision-making, compatibility of structure, trust-based relationships, team-based goals and measures [25]. Network integration facilitates fluid coordination between supply chain partners [25], in particular, shared information between them can only be fully leveraged through process alignment [24]. It includes attributes such as co-managed inventory, collaborative product design, synchronous supply [24], joint product development, cross-functional teams, co-managed inventory, and infrastructure in place to encourage innovation and update the mix of available manufacturing processes in supply chain network [25]. Then, sharing data between supply chain partners, from the manufacturers to the customers [21], is in effect creating a virtual supply chain [25]. Virtual supply chains envisages shared information on real demand, collaborative planning, end-toend visibility [24], access to information, knowledge through the internet, point-of-sale data, efficient consumer response, data mining capabilities, common goals and beliefs, high level of coordination, focus on outsourcing, paperless transactions and new generation of web-based software [25].

To achieve these capabilities agile enablers should be identified and there are two types of these enablers: proactive and reactive [27]. Proactive enablers are preventive mechanisms that enable the supply chain to anticipate and detect environment changes [27]. These enablers are mainly concerned with the supply side of the supply chain [27], such as: process compliance which can used only resources required for the establishment of supply chain agility and respond to supply chain challenges [28], culture of change by using continuous improvement and involving top management and staff to respond to changes, operational alignment in order to enhance operational capabilities [27], entrepreneurial orientation to take advantages of new opportunities [14], collaborative relationship which can help to anticipate possible opportunities and threats through information sharing and to achieve the operational alignment, contingency planning of teams to tackle these disruptions, internal and external integration, strategic orientation to align team capabilities, and supportive information technology to boost connectivity between internal and external members [27].

However, reactive enablers are defensive mechanisms that enable the supply chain to respond to identified changes, these enablers are mainly concerned with changes effect, such as sourcing strategies by selecting and involving key suppliers to maintain supply chain innovativeness, logistics and distribution capabilities to minimize vulnerabilities, strategic flexibility by adapting the supply chain in the face of market changes with minimal penalty, customer demand management [27], resource management [14], financial resources management [29] and real-time information update for all supply chains (Tables 1-3) [25].

Table 1

Competitive bases of agile supply chain

$\begin{array}{ll}\text { CB1 } & \text { Speed } \\ \text { CB2 } & \text { Flexibility } \\ \text { CB3 } & \text { Cost } \\ \text { CB4 } & \text { Quality } \\ \text { CB5 } & \text { Innovation } \\ \text { CB6 } & \text { Proactivity } \\ \text { CB7 } & \text { Responsiveness } \\ \text { CB8 } & \text { New product introduction } \\ \text { CB9 } & \text { Delivery } \\ \text { CB10 } & \text { Concern for the environment and international competitiveness } \\ \text { CB11 } & \text { Profitability }\end{array}$

Adapted from: $[14,18,20,22,24,25,27-29,31]$. 
Table 2

Agile supply chain attributes

\begin{tabular}{|c|c|}
\hline ASCA1 & Volume flexibility \\
\hline ASCA2 & Delivery flexibility \\
\hline ASCA3 & Mix flexibility \\
\hline ASCA4 & Product flexibility \\
\hline ASCA5 & Procurement/sourcing Flexibility \\
\hline ASCA6 & Manufacturing Flexibility \\
\hline ASCA7 & Distribution logistics/Flexibility \\
\hline ASCA8 & Reactivity \\
\hline ASCA9 & Velocity \\
\hline ASCA10 & Visibility \\
\hline ASCA11 & Reliability \\
\hline ASCA12 & Completeness \\
\hline ASCA13 & Productivity \\
\hline ASCA14 & Cost minimization \\
\hline ASCA15 & New product development \\
\hline ASCA16 & Daily P.O.S. feedback \\
\hline ASCA17 & Capture emerging trends \\
\hline ASCA18 & Listen to consumers \\
\hline ASCA19 & Responding to real demand \\
\hline ASCA20 & Demand for customised products \\
\hline ASCA21 & Fast introduction of new products \\
\hline ASCA22 & Retain and grow customer relationships \\
\hline ASCA23 & Customer-based measures \\
\hline ASCA24 & Improved quality \\
\hline ASCA25 & Cost reduction \\
\hline ASCA26 & Increased frequency of product improvements \\
\hline ASCA27 & Leverage partners' capabilities \\
\hline ASCA28 & Focus on core competencies \\
\hline ASCA29 & Act as network orchestrator \\
\hline ASCA30 & Top management commitment to agile practices \\
\hline ASCA31 & Decentralised decision-making \\
\hline ASCA32 & Compatibility of structure \\
\hline ASCA33 & Trust-based relationships \\
\hline ASCA34 & Team-based goals and measures \\
\hline ASCA35 & Co-managed inventory \\
\hline ASCA36 & Collaborative product design \\
\hline ASCA37 & Synchronous supply \\
\hline ASCA38 & Joint product development \\
\hline ASCA39 & Cross-functional teams \\
\hline ASCA40 & Co-managed inventory \\
\hline ASCA41 & Infrastructure in place to encourage innovation \\
\hline ASCA42 & Update the mix of available manufacturing processes in supply chain network \\
\hline ASCA43 & Shared information on real demand \\
\hline ASCA44 & Collaborative planning \\
\hline ASCA45 & End-to-end visibility \\
\hline ASCA46 & Access to information, knowledge through the internet \\
\hline ASCA47 & Point-of-sale data \\
\hline ASCA48 & Efficient consumer response \\
\hline ASCA49 & Data mining capabilities \\
\hline ASCA50 & Common goals and beliefs \\
\hline ASCA51 & High level of coordination \\
\hline ASCA52 & Focus on outsourcing \\
\hline ASCA53 & Paperless transactions \\
\hline ASCA54 & New generation of web-based software \\
\hline
\end{tabular}

Adapted from: $[14,18,20,22,24,25,27-31]$. 
Table 3

Agile supply chain enablers

$\begin{array}{lc}\text { ASCE1 } & \text { Process compliance } \\ \text { ASCE2 } & \text { Sourcing strategies } \\ \text { ASCE3 } & \text { Culture of change } \\ \text { ASCE4 } & \text { Operational alignment } \\ \text { ASCE5 } & \text { Entrepreneurial orientation } \\ \text { ASCE6 } & \text { Collaborative relationship } \\ \text { ASCE7 } & \text { Logistics and distribution capabilities } \\ \text { ASCE8 } & \text { Strategic flexibility } \\ \text { ASCE9 } & \text { Demand management } \\ \text { ASCE10 } & \text { Contingency planning } \\ \text { ASCE11 } & \text { Strategic orientation } \\ \text { ASCE12 } & \text { Internal and external integration } \\ \text { ASCE13 } & \text { Supportive information technology } \\ \text { ASCE14 } & \text { Resource management } \\ \text { ASCE15 } & \text { Financial resources } \\ \text { ASCE16 } & \text { Real-time information update }\end{array}$

Adapted from: $[14,18,20,22,24,25,27-29,31]$.

\section{2. FQFD methodology}

QFD is a powerful approach for enabling a customer-driven system by developing product design [32] and integrating customer requirements (CR) into product or service parameters, which means that these requirements are converted into technical specifications [32]. Since its appearance, QFD has met with varying degrees of success in different field [32], for example [33] used QFD to maximize customer satisfaction, and also [34] applied it to select the best supplier for a supply chain [32]. These results and others showed the practical feasibility of QFD [32].

This approach utilizes house of quality (HOQ) which is a matrix providing information on CRs, determining appropriate design requirements (DRs) to satisfy them, and then establishing relationships between CRs and DRs and correlations between DRs [32]. In our study, QFD and HOQ principles are translated from product design field to the supply chain agility context [8]. Specifically, let's propose to exploit the first HOQ to relate CB to ASCA, then then second HOQ to relate ASCA to ASCE [8]. Relationship ratings were obtained from direct interview of factory experts, and to handle imprecise experts' data, the fuzzy logic was used [32].

The first HOQ aims at identifying the relevant ASCA that enhance company's competitiveness according to $\mathrm{CB}[8]$ and prioritize $\mathrm{CB}$ that enhance the competitiveness of the factory [11]. Then, CB appear as «whats» in the first HOQ while ASCA appear as «hows» [8]. The first step is to rank CB by pondering their importance weights $W_{i=1, \ldots, 11}[8]$ expressed with triangular

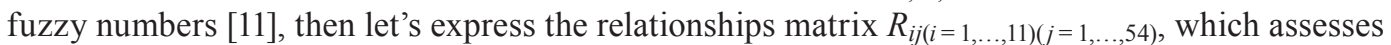
how $\mathrm{ASCA}_{j}$ performs against the $\mathrm{CB}_{i}$, in graphic symbols which are converted then in a rating scale (Table 4) [8]. Once relationships are established, the relative importance $R I_{j}$ of $\mathrm{ASCA}_{j}$ can be computed as a fuzzy weighted average, according to the following (1) [8]:

$$
R I_{j}=\sum_{i=1}^{11} W_{i} \otimes R_{i j} ; j=1, \ldots, 54 .
$$

This is followed by the development of correlation matrix $T_{j j^{\prime}}$ which expresses the correlations between $\mathrm{ASCA}_{j}$ and $\mathrm{ASCA}_{j^{\prime} \neq j}[11]$. The degree of correlations are usually expressed by graphics symbols following a 4-level scale, then translated into fuzzy triangular numbers [8, 11]. The final score of $\mathrm{ASCA}_{j}$ can be computed by using (2) [8]:

$$
\text { Score }_{j}=R I_{j} \otimes \sum_{j \neq j^{\prime}} T_{j j^{\prime}} \otimes R_{i j^{\prime}} ; j=1, \ldots, 54 .
$$


The first HOQ aims determining ASCE satisfying the defined ASCA, which means that ASCA represent the input of HOQ «whats» and ASCE represent the output «hows» [11].

Table 4

Degree of relationship, the graphic symbol and the corresponding fuzzy numbers [8]

\begin{tabular}{ccl}
\hline Degree of relationship & Fuzzy number & \multicolumn{1}{c}{ Description } \\
\hline Strong $(\bullet)$ & $(0.7,1,1)$ & Strong relationship between identified ASCA and CB \\
Medium $(\circ)$ & $(0.3,0.5,0.7)$ & Medium relationship between identified ASCA and CB \\
Weak $(\nabla)$ & $(0,0,0.3)$ & Weak relationship between identified ASCA and CB
\end{tabular}

By following the previously mentioned procedure [11], let's use $R I_{j}$ of various ASCA as importance weights $W_{j}$, then let's express relationships $R_{j k}$ between $\mathrm{ASCE}_{k}$ and $\mathrm{ASCA}_{j}$ and correlations $T_{k k^{\prime}}$ between $\mathrm{ASCE}_{j}$ and $\mathrm{ASCE}_{k}$, and let's obtain the relative importance $R I_{k}$ and the final scores of $\mathrm{ASCE}_{k}$ using the following (3), (4) [8]:

$$
\begin{gathered}
R I_{k}=\sum_{j=1}^{54} W_{j} \otimes R_{j k} ; k=1, \ldots, 16, \\
\operatorname{Score}_{k}=R I_{k} \oplus \sum_{k^{\prime} \neq k} T_{k k^{\prime}} \otimes R I_{k^{\prime}} ; k=1, \ldots, 16 .
\end{gathered}
$$

\section{Results and discussion}

\section{1. FQFD results}

The result of the first HOQ is the ranking of $\mathrm{ASCA}_{j}$ by defuzzifying $\mathrm{Score}_{\mathrm{j}}$ in descending order of importance [11]. To do it, let's calculate the crisp value of the triangular fuzzy number of each $\operatorname{Score}_{j}(l, m, u)$ using (5) [11]. Then, $\mathrm{ASCA}_{j}$ with the highest score influence significantly $\mathrm{CB}_{i}[11]$. Some results are presented in Fig. 1.

$$
\text { CrispValue }=\frac{1+2 m+u}{4}
$$

For the second HOQ, let's apply (5) to defuzzified scores in order to rank $\mathrm{ASCE}_{k}$ [8], again

\begin{tabular}{|c|c|c|c|c|c|c|}
\hline & $\mathbf{W i}$ & ASCA1 & ASCA2 & ASCA3 & ASCA4 & ASCA5 \\
\hline CB1 & VL & & $\nabla$ & $\nabla$ & $\bullet$ & $\circ$ \\
\hline CB2 & H & $\bullet$ & o & & $\bullet$ & $\nabla$ \\
\hline CB3 & VH & 0 & & $\bullet$ & $\circ$ & \\
\hline CB4 & VH & 0 & $\bullet$ & $\bullet$ & 0 & \\
\hline CB5 & $\mathbf{H}$ & $\bullet$ & $\bullet$ & & & \\
\hline CB6 & VL & 0 & $\bullet$ & & $\bullet$ & $\bullet$ \\
\hline CB7 & $\mathbf{L}$ & 0 & & 0 & & \\
\hline CB8 & VH & 0 & $\bullet$ & & $\nabla$ & $\bullet$ \\
\hline CB9 & H & $\bullet$ & $\nabla$ & $\bullet$ & $\nabla$ & \\
\hline CB10 & $\mathbf{H}$ & 0 & & & & $\nabla$ \\
\hline CB11 & $\mathbf{H}$ & $\nabla$ & o & $\nabla$ & $\nabla$ & o \\
\hline \multicolumn{2}{|r|}{$\mathbf{R I j}$} & $\begin{array}{l}1.83 ; \\
4.10 ; \\
6.66)\end{array}$ & $\begin{array}{l}(1.63 ; \\
3.40 \\
5.09)\end{array}$ & $\begin{array}{l}(1.33 ; \\
2.85 \\
3.74)\end{array}$ & $\begin{array}{c}0.77 \\
1.70 \\
3.90)\end{array}$ & $\begin{array}{c}0.64 ; \\
1.35 ; \\
2.81)\end{array}$ \\
\hline \multicolumn{2}{|r|}{ Scorej } & $\begin{array}{c}(2.421 ; \\
6.515 ; \\
11.975)\end{array}$ & $\begin{array}{c}(2.374 ; \\
6.600 ; \\
13.312)\end{array}$ & $\begin{array}{c}(1.567 \\
3.700 \\
5.630)\end{array}$ & $\begin{array}{l}(0.770 \\
2.465 \\
6.580)\end{array}$ & $\begin{array}{c}(1.108 ; \\
3.615 ; \\
9.085)\end{array}$ \\
\hline & CrispValue & 6.8565 & 7.2215 & 3.64925 & 3.07 & 4.35575 \\
\hline
\end{tabular}
high crisp values show those enablers that must be selected to enhance ASCA. Some results of the second HOQ are shown in Fig. 2 [11].

Fig. 1. Developed first HOQ 


\begin{tabular}{|c|c|c|c|c|c|c|c|c|c|}
\hline & $\mathbf{W j}$ & ASCE1 & ASCE7 & ASCE8 & ASCE9 & ASCE10 & ASCE11 & ASCE12 & ASCE13 \\
\hline ASCA1 & $(1.83 ; 4.10 ; 6.66)$ & $\bullet$ & $\nabla$ & 0 & & & $\bullet$ & & \\
\hline ASCA2 & $(1.63 ; 3.40 ; 5.09)$ & 0 & & $\bullet$ & & & & & $\bullet$ \\
\hline ASCA32 & $(0.64 ; 1.35 ; 1.79)$ & & & & & & & & \\
\hline ASCA33 & $(0.15 ; 0.35 ; 1.30)$ & & & & & & & & $\bullet$ \\
\hline ASCA53 & $(0.92 ; 2.05 ; 3.19)$ & & & $\nabla$ & & & & & \\
\hline & RIk & $\begin{array}{l}(5.157 ; \\
17.100 ; \\
35.055)\end{array}$ & $\begin{array}{c}(2.596 ; \\
8.400 ; \\
17.616)\end{array}$ & $\begin{array}{c}(3.048 ; \\
9.775 ; \\
20.690)\end{array}$ & $\begin{array}{c}(2.568 ; \\
8.200 ; \\
17.763)\end{array}$ & $\begin{array}{l}(1.260 \\
4.300 \\
7.942)\end{array}$ & $\begin{array}{c}(2.442 ; \\
8.150 ; \\
16.679)\end{array}$ & $\begin{array}{c}1.879 \\
6.125 \\
11.110)\end{array}$ & $\begin{array}{l}(4.717 ; \\
15.000 \\
26.818)\end{array}$ \\
\hline & Scorek & $\begin{array}{c}5.9358 \\
24.6900 \\
47.3862)\end{array}$ & $\begin{array}{l}\text { (3.5281; } \\
15.9550 ; \\
31.2681)\end{array}$ & $\begin{array}{c}(3.048 ; \\
9.775 \\
20.690)\end{array}$ & $\begin{array}{c}(2.568 ; \\
8.200 ; \\
17.763)\end{array}$ & $\begin{array}{c}(1.260, \\
7.330 \\
7.942)\end{array}$ & $\begin{array}{c}(2.442 ; \\
8.150 ; \\
16.679)\end{array}$ & $\begin{array}{c}(1.879 ; \\
6.125 ; \\
11.110)\end{array}$ & $\begin{array}{l}(5.1922, \\
17.7250, \\
35.6968)\end{array}$ \\
\hline & rispValue & 25.6755 & 16.67655 & 10.822 & 9.18275 & 5.9655 & 8.85525 & 6.30975 & 19.08475 \\
\hline
\end{tabular}

Fig. 2. Developed second HOQ

\section{2. Discussion}

According to the first HOQ, high crisp values indicate that ASCA1 (Volume flexibility) has got the highest value followed by ASCA2 (Delivery flexibility). Then the second HOQ shows that ASCE1 has got the highest crisp value which means that ASCE1 (Process compliance) improve the supply chain agility of the factory by minimizing or eliminating risk in the supply chain through captured information about products and processes from the beginning of the life cycle. ASCE7 (Logistics and distribution capabilities) has the next priority as it eliminates or minimizes unnecessary costs. As the logistics and distribution capability increases the delivery speed, distributors' costs are minimized and thus the supply chain agility increases. Supportive information technology (ASCE13) is the third priority as it guarantees fast and fluid communication between the various components of the supply chain which contributes to minimize coordination and transaction costs.

Regarding our purpose, these results presented the main obstacles to improvement of automotive supply chain agility:

- process compliance: In times of COVID-19, automotive industry must focus on addressing a striking array of compliance issues like changes management;

- logistics and distribution capabilities: Automotive industry should reshape the logistics operating model to improve its resilience in times of COVID-19. This new model takes into account the new logistics market information and requirement;

- supportive information technology: By measuring technology business value, automotive industry could identify the contribution of information technology in its supply chain productivity; and then ameliorate its supply chain performance.

Thus, the proposed results allow to faced the major disruptions caused by COVID-19 crisis, by radically focusing on digital channels, implementing the right capabilities and the process operations to build an agile supply chain.

The implementation of the proposals suggested in the case study has lead to the identification of the agile supply chain attributes and enablers needed to take the vital agile decision to deal with COVID-19 pandemic. Indeed, our research indicates the feasibility of deploying FQFD approach in the Moroccan automotive industry, especially in times of COVID-19. Hence, the findings are original. However, the application of the FQFD methodology to a real case requires some initial efforts as the formation of supply chain teams and managers; management involvement and support and team coordination in order to build a successful FQFD programme in the factory. As a future research direction, let's propose to adapt our approach to lean or liability supply chain context, as the agility are usually linked to these concepts. Also, COVID-19 has impacted different supply chains from different sectors, more case studies could be carried out.

\section{Conclusions}

In order to prioritize the $\mathrm{CB}$, a FQFD has been applied for enhancing the supply chain agility of a Moroccan automative factory. The inputs are the ASCA with importance values and the output are the ASCE needed to be implemented by the factory. By building two HOQs; the first between CB and ASCA and the second between ASCA and ASCE; the results showed that the prioritized enablers are ASCE1, ASCE7 and ASCE13 which help to improve the supply chain agility. 
These prioritized ASCE enabled the factory to identify the areas that could be improved to achieve the competitive advantage in times of COVID-19.

The main advantages of our results can be summarised as follows:

- precising a specified taxonomy of ASCA and ASCE that the factory perceive as important to achieve supply chain agility;

- describing possible relationships and correlations between ASCA and ASCE by showing those impacting the score ranking of ASCA and ASCE.

\section{Acknowledgments}

The authors acknowledge the financial support of the National Centre for Scientific and Technical Research (CNRST) under the Excellence Research Scholarships Program.

\section{References}

[1] Haq, A. N., Boddu, V. (2014). Analysis of enablers for the implementation of leagile supply chain management using an integrated fuzzy QFD approach. Journal of Intelligent Manufacturing, 28 (1), 1-12. doi: https://doi.org/10.1007/s10845-014-0957-9

[2] Lin, C.-T., Chiu, H., Chu, P.-Y. (2006). Agility index in the supply chain. International Journal of Production Economics, 100 (2), 285-299. doi: https://doi.org/10.1016/j.ijpe.2004.11.013

[3] Al-Shboul, M. A. (2017). Infrastructure framework and manufacturing supply chain agility: the role of delivery dependability and time to market. Supply Chain Management: An International Journal, 22 (2), 172-185. doi: https://oi.org/10.1108/scm09-2016-0335

[4] Singh Patel, B., Samuel, C., Sharma, S. K. (2017). Evaluation of agility in supply chains: a case study of an Indian manufacturing organization. Journal of Manufacturing Technology Management, 28 (2), 212-231. doi: https://doi.org/10.1108/jmtm09-2016-0125

[5] Mehralian, G., Zarenezhad, F., Rajabzadeh Ghatari, A. (2015). Developing a model for an agile supply chain in pharmaceutical industry. International Journal of Pharmaceutical and Healthcare Marketing, 9 (1), 74-91. doi: https://doi.org/10.1108/ ijphm-09-2013-0050

[6] Abdoli Bidhandi, R., Valmohammadi, C. (2017). Effects of supply chain agility on profitability. Business Process Management Journal, 23 (5), 1064-1082. doi: https://doi.org/10.1108/bpmj-05-2016-0089

[7] Gligor, D. M., Holcomb, M. C. (2012). Understanding the role of logistics capabilities in achieving supply chain agility: a systematic literature review. Supply Chain Management: An International Journal, 17 (4), 438-453. doi: https://doi.org/ 10.1108/13598541211246594

[8] Bottani, E. (2009). A fuzzy QFD approach to achieve agility. International Journal of Production Economics, 119 (2), $380-391$. doi: https://doi.org/10.1016/j.ijpe.2009.02.013

[9] Aslam, H., Blome, C., Roscoe, S., Azhar, T. M. (2018). Dynamic supply chain capabilities: How market sensing, supply chain agility and adaptability affect supply chain ambidexterity. International Journal of Operations \& Production Management, 38 (12), 2266-2285. doi: https://doi.org/10.1108/ijopm-09-2017-0555

[10] I. van Hoek, R., Harrison, A., Christopher, M. (2001). Measuring agile capabilities in the supply chain. International Journal of Operations \& Production Management, 21 (1/2), 126-148. doi: https://doi.org/10.1108/01443570110358495

[11] Vinodh, S., Chintha, S. K. (2011). Application of fuzzy QFD for enabling agility in a manufacturing organization: A case study. The TQM Journal, 23 (3), 343-357. doi: https://doi.org/10.1108/17542731111124389

[12] Shashi, Centobelli, P., Cerchione, R., Ertz, M. (2020). Agile supply chain management: where did it come from and where will it go in the era of digital transformation? Industrial Marketing Management, 90, 324-345. doi: https://doi.org/10.1016/ j.indmarman.2020.07.011

[13] Li, X., Goldsby, T. J., Holsapple, C. W. (2009). Supply chain agility: scale development. The International Journal of Logistics Management, 20 (3), 408-424. doi: https://doi.org/10.1108/09574090911002841

[14] Irfan, M., Wang, M., Akhtar, N. (2019). Enabling supply chain agility through process integration and supply flexibility: Evidence from the fashion industry. Asia Pacific Journal of Marketing and Logistics, 32 (2), 519-547. doi: https://doi.org/10.1108/ apjml-03-2019-0122

[15] Jindal, A., Sharma, S. K., Sangwan, K. S., Gupta, G. (2021). Modelling Supply Chain Agility Antecedents Using Fuzzy DEMATEL. Procedia CIRP, 98, 436-441. doi: https://doi.org/10.1016/j.procir.2021.01.130

[16] Qrunfleh, S., Tarafdar, M. (2013). Lean and agile supply chain strategies and supply chain responsiveness: the role of strategic supplier partnership and postponement. Supply Chain Management: An International Journal, 18 (6), 571-582. doi: https://doi.org/ 10.1108/scm-01-2013-0015 
[17] Prater, E., Biehl, M., Smith, M. A. (2001). International supply chain agility - Tradeoffs between flexibility and uncertainty. International Journal of Operations \& Production Management, 21 (5/6), 823-839. doi: https://doi.org/10.1108/01443570110390507

[18] Yusuf, Y. Y., Sarhadi, M., Gunasekaran, A. (1999). Agile manufacturing: The drivers, concepts and attributes. International Journal of Production Economics, 62 (1-2), 33-43. doi: https://doi.org/10.1016/s0925-5273(98)00219-9

[19] Dove, R. (1999). Knowledge management, response ability, and the agile enterprise. Journal of Knowledge Management, 3 (1), 18-35. doi: https://doi.org/10.1108/13673279910259367

[20] Charles, A., Lauras, M., Van Wassenhove, L. (2010). A model to define and assess the agility of supply chains: building on humanitarian experience. International Journal of Physical Distribution \& Logistics Management, 40 (8/9), 722-741. doi: https://doi.org/10.1108/09600031011079355

[21] Kumar Sharma, S., Bhat, A. (2014). Modelling supply chain agility enablers using ISM. Journal of Modelling in Management, 9 (2), 200-214. doi: https://doi.org/10.1108/jm2-07-2012-0022

[22] Pilevari, N., SeyedHosseini, S. M., Jassbi, J. (2008). Fuzzy logic Supply Chain Agility Assessment methodology. 2008 IEEE International Conference on Industrial Engineering and Engineering Management. doi: https://doi.org/10.1109/ ieem.2008.4738043

[23] Lin, C.-T., Chiu, H., Tseng, Y.-H. (2006). Agility evaluation using fuzzy logic. International Journal of Production Economics, 101 (2), 353-368. doi: https://doi.org/10.1016/j.ijpe.2005.01.011

[24] Christopher, M., Lowson, R., Peck, H. (2004). Creating agile supply chains in the fashion industry. International Journal of Retail \& Distribution Management, 32 (8), 367-376. doi: https://doi.org/10.1108/09590550410546188

[25] Faisal, M. N., Banwet, D. K., Shankar, R. (2007). An approach to measure supply chain agility. International Journal of Industrial and Systems Engineering, 2 (1), 79. doi: https://doi.org/10.1504/ijise.2007.011438

[26] Yusuf, Y. Y., Gunasekaran, A., Adeleye, E. O., Sivayoganathan, K. (2004). Agile supply chain capabilities: Determinants of competitive objectives. European Journal of Operational Research, 159 (2), 379-392. doi: https://doi.org/10.1016/j.ejor.2003.08.022

[27] Al Humdan, E., Shi, Y., Behnia, M. (2020). Supply chain agility: a systematic review of definitions, enablers and performance implications. International Journal of Physical Distribution \& Logistics Management, 50 (2), 287-312. doi: https://oi.org/ 10.1108/ijpdlm-06-2019-0192

[28] Blome, C., Schoenherr, T., Rexhausen, D. (2013). Antecedents and enablers of supply chain agility and its effect on performance: a dynamic capabilities perspective. International Journal of Production Research, 51 (4), 1295-1318. doi: https://doi.org/ 10.1080/00207543.2012.728011

[29] Pandey, V. C., Garg, S. (2009). Analysis of interaction among the enablers of agility in supply chain. Journal of Advances in Management Research, 6 (1), 99-114. doi: https://doi.org/10.1108/09727980910972190

[30] Faisal, M. N., Banwet, D. K., Shankar, R. (2007). Supply chain agility: analysing the enablers. International Journal of Agile Systems and Management, 2 (1), 76. doi: https://doi.org/10.1504/ijasm.2007.015682

[31] Li, X., Chung, C., Goldsby, T. J., Holsapple, C. W. (2008). A unified model of supply chain agility: the work-design perspective. The International Journal of Logistics Management, 19 (3), 408-435. doi: https://doi.org/10.1108/09574090810919224

[32] Mohanraj, R., Sakthivel, M., Vinodh, S., Vimal, K. E. K. (2015). A framework for VSM integrated with Fuzzy QFD. The TQM Journal, 27 (5), 616-632. doi: https://doi.org/10.1108/tqm-11-2012-0088

[33] Chen, L.-H., Ko, W.-C. (2010). Fuzzy linear programming models for NPD using a four-phase QFD activity process based on the means-end chain concept. European Journal of Operational Research, 201 (2), 619-632. doi: https://doi.org/10.1016/ j.ejor.2009.03.010

[34] Vinodh, S., Rathod, G., Devadasan, S. R. (2011). Application of QFD for supplier selection in an Indian electronics switches manufacturing organisation. International Journal of Indian Culture and Business Management, 4 (2), 181. doi: https://doi.org/ 10.1504/ijicbm.2011.038916

Received date 02.08.2021

(C) The Author(s) 2021

Accepted date 07.11.2021

This is an open access article

Published date 18.11.2021

under the Creative Commons CC BY license

How to cite: Tamtam, F., Tourabi, A. (2021). Analysis of the agility of the automotive industry supply chain in times of COVID-19: a case study. EUREKA: Physics and Engineering, 6, 112-120. doi: https://doi.org/10.21303/2461-4262.2021.001949 